\title{
Indications of beta-adrenoceptor blockers in Takotsubo syndrome and theoretical reasons to prefer agents with vasodilating activity
}

\author{
Alberto Aimo ${ }^{\mathrm{a}, \mathrm{b}, *}$, Francesco Pelliccia ${ }^{\mathrm{c}}$, Giorgia Panichella ${ }^{\mathrm{a}}$, Giuseppe Vergaro ${ }^{\mathrm{a}, \mathrm{b}}$, Andrea Barison ${ }^{\mathrm{a}, \mathrm{b}}$, \\ Claudio Passino a,b ${ }^{\mathrm{a}}$, Michele Emdin ${ }^{\mathrm{a}, \mathrm{b}}$, Paolo G. Camici ${ }^{\mathrm{d}}$ \\ a Institute of Life Sciences, Scuola Superiore Sant'Anna, Pisa, Italy \\ b Cardiology Division, Fondazione Toscana Gabriele Monasterio, Pisa, Italy \\ c Department of Cardiovascular Sciences, Sapienza University, Rome, Italy \\ d San Raffaele Hospital and Vita Salute University, Milan, Italy
}

\section{A R T I C L E I N F O}

\section{Article history:}

Received 23 February 2021

Accepted 25 February 2021

Available online 2 March 2021

\section{Keywords:}

Myocardial infarction

Takotsubo syndrome

Sympathetic activation

$\beta$-Blockers

\begin{abstract}
A B S T R A C T
Takotsubo syndrome (TTS) is estimated to account for 1-3\% of all patients presenting with suspected ST-segment elevation myocardial infarction. A sudden surge in sympathetic nervous system is considered the cause of TTS. Nonetheless, no specific recommendations have been provided regarding $\beta$-blocking therapy. Apart from specific contra-indications (severe LV dysfunction, hypotension, bradycardia and corrected QT interval $>500 \mathrm{~ms}$ ), treatment with a $\beta$-blocker seems reasonable until full recovery of LV ejection fraction, though evidence is limited to a few animal studies, case reports or observational studies. In this review, we will reappraise the rationale for $\beta$-blocker therapy in TTS and speculate on the pathophysiologic basis for preferring non-selective agents with vasodilating activity over $\beta_{1}$-selective drugs.
\end{abstract}

(C) 2021 Elsevier B.V. All rights reserved.
Takotsubo syndrome (TTS) is characterized by transient left ventricular (LV) systolic dysfunction triggered by physical or emotional factors with clinical features resembling those of an acute coronary syndrome [1-3]. Its typical presentation consists in a dilation and dysfunction of apical LV segments (apical ballooning) with preserved or increased contractility of basal segments that may lead to LV outflow tract obstruction (LVOTO) in about $20 \%$ of cases [4] (Table 1). No specific medical treatment has been demonstrated to protect against in-hospital mortality and promote the short-term recovery from LV dysfunction [5]. Equally, there is no medication able to prevent recurrences. Retrospective registry data have shown that angiotensin converting enzyme inhibitors (ACEi) and angiotensin-receptor blockers (ARBs), but not $\beta$-blockers, are associated with improved survival at one-year follow-up in patients with or without heart failure (HF) [3]. However, randomized clinical trials with pre-specified end-points are lacking, and therefore no definitive data on the safety and efficacy of agents are available. In this review, we will focus on the rationale and possible applications of $\beta$ blockers in patients with TTS, and the theoretical reasons to prefer $\beta$ blockers with a vasodilating activity due to concomitant $\alpha_{1}$ adrenoceptor blockade.

\footnotetext{
* Corresponding author at: Institute of Life Sciences, Scuola Superiore Sant'Anna, and Cardiology Division, Fondazione Toscana Gabriele Monasterio, Piazza Martiri della Libertà 33, 56124 Pisa, Italy.

E-mail addresses: a.aimo@santannapisa.it, aimoalb@ftgm.it (A. Aimo).
}

\section{Current recommendations about $\beta$-blockers in TTS}

During the acute phase, $\beta$-blockers should be considered in patients with mild forms of TTS, either with or without HF, and in those with HF or pulmonary edema. Furthermore, patients with hypotension or cardiogenic shock and evidence of LVOTO might benefit from the infusion of short-acting $\beta$-blockers, which might rapidly relieve LVOTO. $\beta$ blockers might also be considered in patients with arrhythmias (for example, ventricular tachycardia or fibrillation), but should be avoided when patients are bradycardic and have a corrected QT interval $>500$ ms. Finally, $\beta$-blockers have not been recommended for chronic treatment after discharge (Fig. 1). These suggestions for patient management are reported in an international consensus document and rely on expert opinion, in the absence of specific evidence [5]. (See Fig. 2.)

\section{Evidence on $\beta$-blockers in TTS}

Data about $\beta$-blocker therapy during the acute phase of TTS are limited to a few animal studies showing that the apical ballooning is attenuated after the administration of metoprolol (a selective $\beta_{1}$-blocker) [6], or amosulalol (a drug with a much higher affinity for $\alpha_{1}$-adrenoceptors than for $\beta$-receptors) [7], and to some case reports or observational studies [8-11] (Table 2).

After the acute phase, long-term $\beta$-blocker therapy has been proposed to prevent TTS recurrence or attenuate its clinical severity by 
Table 1

The International Takotsubo (InterTAK) diagnostic criteria.

1. Patients show transient ${ }^{\mathrm{a}} \mathrm{LV}$ dysfunction (hypokinesia, akinesia, or dyskinesia) presenting as apical ballooning or midventricular, basal, or focal wall motion abnormalities. RV involvement can be present. Besides these regional wall motion patterns, transitions between all types can exist. The regional wall motion abnormality usually extends beyond a single epicardial vascular distribution; however, rare cases can exist where the regional wall motion abnormality is present in the subtended myocardial territory of a single coronary artery (focal TTS) ${ }^{\mathrm{b}}$.

2. An emotional, physical, or combined trigger can precede the TTS event, but this is not obligatory.

3. Neurologic disorders (e.g., subarachnoid hemorrhage, stroke/TIA, or seizures) as well as pheochromocytoma may serve as triggers for TTS.

4. New ECG abnormalities are present (ST-segment elevation, ST-segment depression, T-wave inversion, and QTc prolongation); however, rare cases exist without any ECG changes.

5. Levels of cardiac biomarkers (troponin and creatine kinase) are moderately elevated in most cases; significant elevation of BNP is common.

6. Significant CAD is not a contradiction in TTS.

7. Patients have no evidence of infectious myocarditis ${ }^{\mathrm{b}}$.

8. Postmenopausal women are predominantly affected.

a Regional wall motion abnormalities may remain for a prolonged period of time or documentation of recovery may not be possible. For example, death before evidence of recovery is captured.

b Cardiac magnetic resonance imaging is recommended to exclude infectious myocarditis and diagnosis confirmation of TTS. BNP, B-type natriuretic peptide; CAD, coronary artery disease; ECG, electrocardiogram; LV, left ventricular; RV, right ventricular; TIA, transient ischemic attack; TTS, Takotsubo syndrome. Adapted from: Ghadri et al., 2018 [5]. blunting the effects of further catecholamine surges. However, no study has proven any clear benefit of long-term treatment with $\beta$-blockers so far. In a registry of 1750 patients, Templin et al. showed comparable death rates at 1 year whether patients with TTS are treated with $\beta$ blockers or not [3]. In an observational study of 2672 patients, $\beta$ blockers were unable to lower 30-day mortality [10]. A meta-analysis by Singh et al. concluded that $\beta$-blockers do not prevent TTS recurrence, contrary to ACE inhibitors [12]. Similarly, the meta-analysis by Bonacchi et al. including 8 studies and 511 patients found no difference in terms of recurrence rate between patients receiving $\beta$-blockers and those who were not [13], and the meta-analysis by Santoro showed that TTS severity is not affected by pre-treatment with low-dose $\beta$-blockers [14].

In summary, available data on $\beta$-blockers in both the acute and subacute phases of TTS have yielded unclear results. A potential explanation of the controversial findings reported so far may lie on the fact that the optimal use of $\beta$-blockers in TTS requires understanding of the complex pathophysiologic mechanisms underlying this condition.

\subsection{Pathophysiology of TTS and role of sympathetic activation}

The sympathetic nervous system regulates both inotropic and chronotropic cardiac functions as well as vasomotion directly, through norepinephrine released from its myocardial nerve endings, and indirectly, through circulating catecholamines released from the adrenal gland. In addition, increased catecholamine levels promote positive

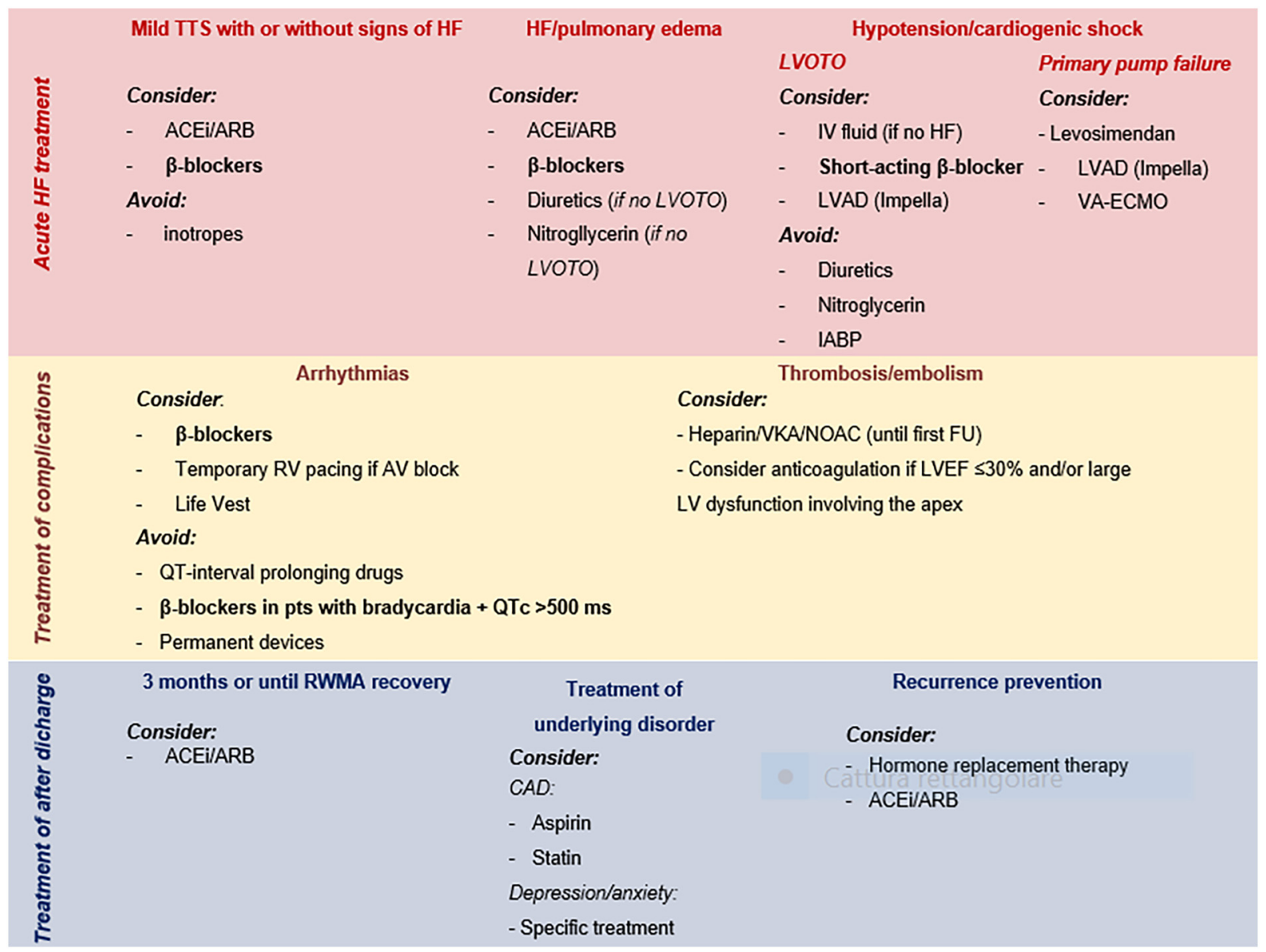

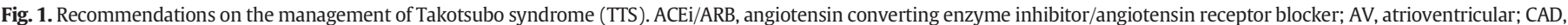

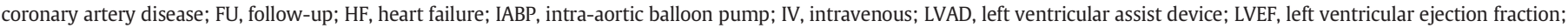

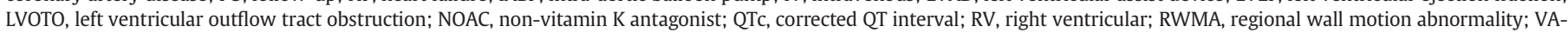
ECMO, venoarterial extracorporeal membrane oxygenation; VKA, vitamin K antagonist. Modified with permission from: Ghadri JR et al., 2018 [5]. 


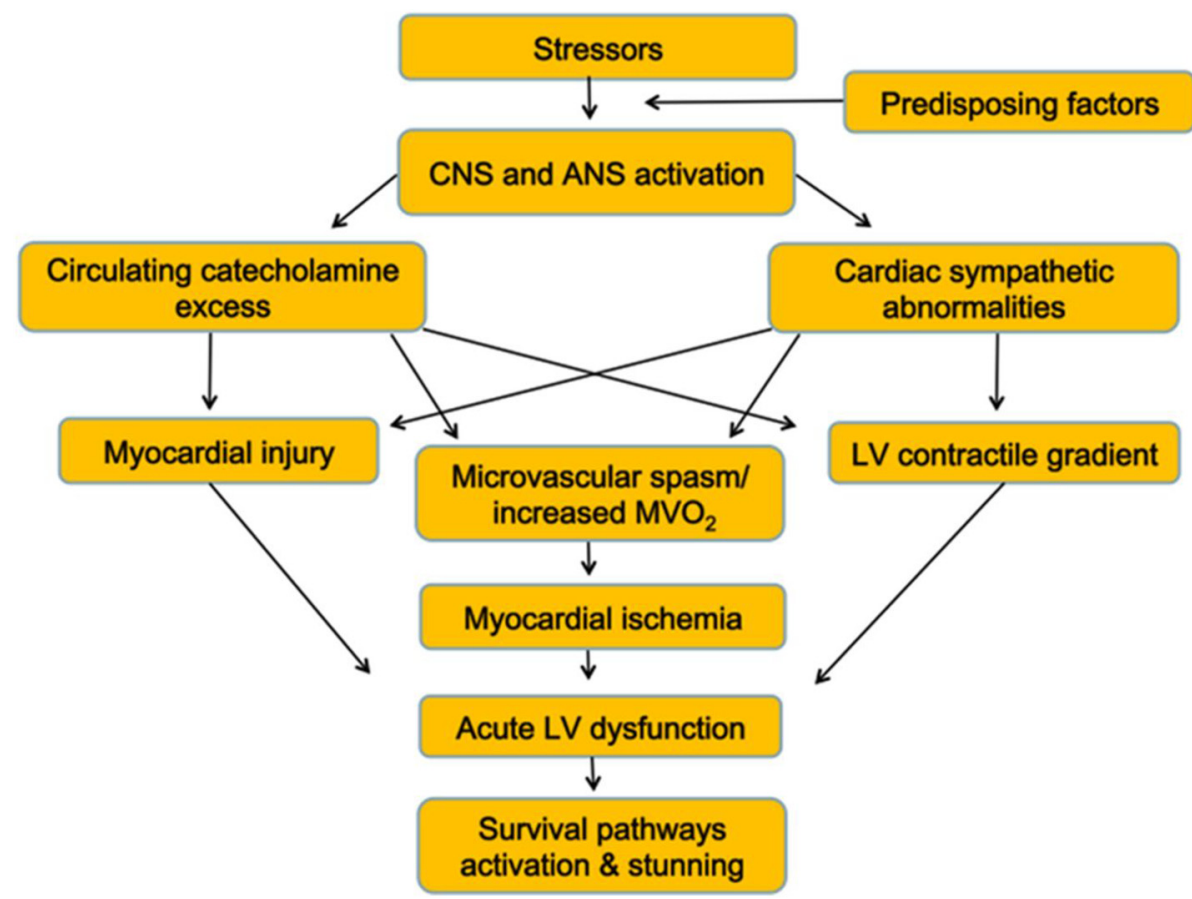

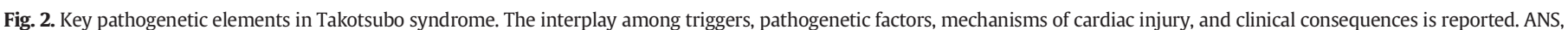
autonomic nervous system; CNS, central nervous system; LV, left ventricular; $\mathrm{MVo}_{2}$, myocardial oxygen consumption. Reprinted with permission from: Pelliccia F et al., 2017 [24].

Table 2

Studies assessing the effects of $\beta$-blocker therapy during the acute phase of Takotsubo syndrome (TTS).

\begin{tabular}{|c|c|c|c|c|}
\hline Study & Type of study & Drug & Receptors targeted & Main results \\
\hline Ueyama et al., 2002 [7] & $\begin{array}{l}\text { Preclinical (rats with } \\
\text { emotion-induced TTS) }\end{array}$ & Amosulalol & $\alpha_{1} \beta_{1} \beta_{2}$ & $\begin{array}{l}\text { LV apical ballooning prevented by } \\
\text { pre-treatment with amosulalol. }\end{array}$ \\
\hline Izumi et al., 2009 [6] & $\begin{array}{l}\text { Preclinical (monkey with } \\
\text { epinephrine-induced TTS) }\end{array}$ & Metoprolol & $\beta_{1}$ & $\begin{array}{l}\text { Earlier LVEF recovery and diminished } \\
\text { cardiomyocytolysis. }\end{array}$ \\
\hline Kumar et al., 2011 [11] & $\begin{array}{l}\text { Clinical (collection of case } \\
\text { reports on patients with TTS) }\end{array}$ & Several $\beta$-blockers & - & $\begin{array}{l}\beta \text {-blocker therapy may have protective } \\
\text { effect against cardiac rupture. }\end{array}$ \\
\hline Santoro et al., 2016 [9] & $\begin{array}{l}\text { Clinical (retrospective } \\
\text { observational study, patients } \\
\text { with TTS and LVOTO) }\end{array}$ & Esmolol & $\beta_{1}$ & $\begin{array}{l}\text { Esmolol infusion temporally associated } \\
\text { with reduction in intraventricular } \\
\text { gradient and systemic blood pressure. }\end{array}$ \\
\hline Isogai et al., 2016 [10] & $\begin{array}{l}\text { Clinical (retrospective } \\
\text { observational study, patients } \\
\text { with TTS) }\end{array}$ & $\begin{array}{l}\text { Several } \beta \text {-blockers: propranolol, } \\
\text { landiolol, esmolol, carvedilol, } \\
\text { bisoprolol, others }\end{array}$ & $\begin{array}{l}\beta_{1} \beta_{2} \text { (propranolol) } \beta_{1} \\
\text { (landiolol, esmolol, bisoprolol) } \\
\alpha_{1} \beta_{1} \beta_{2} \text { (carvedilol) }\end{array}$ & $\begin{array}{l}\text { No significant association between early } \\
\beta \text {-blocker use and in-hospital mortality. }\end{array}$ \\
\hline
\end{tabular}

LVEF, left ventricular ejection fraction; LVOTO, left ventricular outflow tract obstruction.

lusitropy, enabling the heart to relax more rapidly. This effect is mediated by the phosphorylation of phospholamban and troponin I via a cyclic adenosine monophosphate-dependent pathway. Catecholamine-induced calcium influx into the sarcoplasmic reticulum increases both inotropy and lusitropy [15].

Considerable evidence exists of an association between a sudden surge in sympathetic activity and TTS. This includes: a) the frequency of emotional or physical triggers, b) the possibility to experimentally induce TTS by intravenous infusion of catecholamines and $\beta$-agonists, c) the evidence of adrenergic activation from measurement of circulating catecholamines, heart rate variability studies, microneurography, and myocardial scintigraphy with ${ }^{123}$ I-meta-iodobenzylguanidine [2], and d) the histopathologic finding of contraction band necrosis typical of direct catecholaminergic toxicity [16]. A cause-effect relationship is thought to exist between sympathetic activation and TTS.

The paroxysmal sympathetic activation may lead to LV dysfunction through multiple mechanisms, including 1) a spasm of small arteries and arterioles causing myocardial ischemia followed by stunning, 2) direct toxic effects of catecholamines on cardiomyocytes, and 3 ) the activation of cellular survival pathways that may contribute to the transient impairment of LV contraction (Fig. 1). These mechanisms are not mutually exclusive and their relative importance may vary in each individual patient.

\subsection{Spasm of small arteries and arterioles}

Both $\alpha$ - and $\beta$-adrenoceptors are present in the coronary vasculature, but with different distributions. The large epicardial coronary arteries have a conduit function and offer little resistance to coronary blood flow. Small arteries have diameters ranging from 100 to $500 \mu \mathrm{m}$, are characterized by a measurable pressure drop along their length, are not controlled by myocardial metabolites, and express $\alpha_{1}$-adrenoceptors, whose activation promotes vasoconstriction [17]. Arterioles have diameters of less than $100 \mu \mathrm{m}$ and are characterized by a considerable drop in pressure along their path. They are the site of metabolic regulation of blood flow, as their tone is influenced by metabolites produced by surrounding cardiomyocytes [17], and express both $\alpha_{1}$ - and $\alpha_{2}$-adrenoceptors, which induce vasoconstriction, as 
well as $\beta_{2}$-adrenoceptors, which mediate vasodilation [18-20]. Physiologically, small coronary arteries and arterioles are the main determinants of coronary vascular resistances. In healthy subjects, the overall response to a physiologic sympathetic activation is vasodilatation mainly through activation of coronary $\beta_{2}$-adrenoceptors. Conversely, increased cardiac sympathetic activity can induce coronary microvascular constriction, instead of the vasodilatation observed normally, in patients with endothelial dysfunction (a condition commonly found in TTS [21]), because $\alpha$-adrenergic vasoconstriction becomes unrestrained and powerful enough to reduce coronary blood flow, thus contributing to myocardial ischemia [20].

Abnormal coronary vasomotion has been documented in TTS with invasive and noninvasive diagnostic tools. Using myocardial contrast echocardiography, Galiuto et al. demonstrated reversible coronary microvascular dysfunction in patients with TTS [22], with a clear perfusion defect in the dysfunctional LV segments. This perfusion defect improved transiently after intracoronary adenosine infusion, and recovered permanently over 1 month. Using positron emission tomography during the acute phase of TTS, Feola et al. demonstrated an impairment of tissue metabolism in the dysfunctional myocardium; this impairment was particularly evident in the apex and became progressively less evident in the midventricular myocardium, and disappeared at 3-month follow-up [23]. In the same study, hyperemic myocardial blood flow and coronary flow reserve were shown to be reduced in dysfunctional myocardium, and, similarly to the metabolic changes, these abnormalities recovered at 3-month follow-up. In summary, reduced contractility observed in TTS may be due, at least in part, to microvascular ischemia followed by myocardial stunning $[24,25]$.

\subsection{Catecholamine toxicity}

An increase in plasma catecholamines to supra-physiological levels causes an overactivation of the $\beta 1$-adrenoceptor-protein kinase-A pathway, which leads to intracellular calcium overload and oxidative stress, and ultimately cardiomyocyte necrosis and apoptosis resulting, histologically, in contraction band necrosis, which is one of the pathological hallmarks of TTS [26-29]. Catecholamine released directly into the myocardium via sympathetic nerves has been suggested to have a greater "toxic" effect than that reaching the heart via the bloodstream [30].

\subsection{Activation of survival pathways}

There is experimental evidence that high epinephrine levels (but not norepinephrine) [31] induce a switch in the protein coupled to $\beta$ adrenoceptors from a stimulatory protein $(\mathrm{G} \alpha \mathrm{s})$ to an inhibitory protein (Goi). This switch is mediated by G-protein-coupled receptor kinase 2 and $\beta$-arrestin [32], and has been demonstrated for $\beta_{2}$-adrenoceptors [31], which exhibit a 35-fold higher affinity for epinephrine than for norepinephrine [33]. Interestingly, the apical LV segments have a $40 \%$ lower density of sympathetic nerve terminals [34] (which release norepinephrine), and the highest concentration of $\beta$-adrenoceptors [34] and the $\beta 2$ isoform [35]. This could explain the regional difference in the response to high catecholamine levels, with circulating epinephrine having a greater influence on apical function, and the G-protein switch explaining the depression of apical contractility characteristic of TTS $[35,36]$.

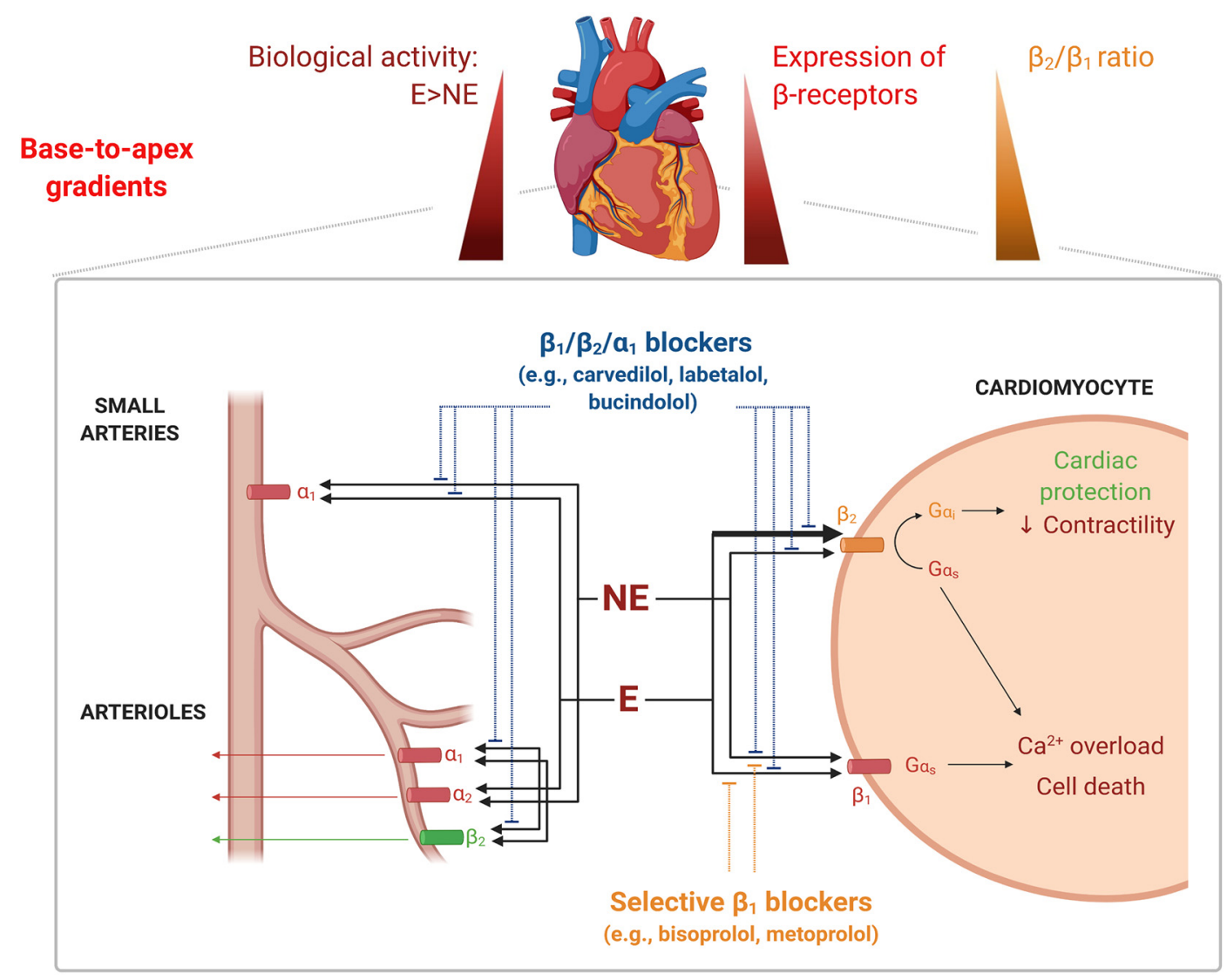

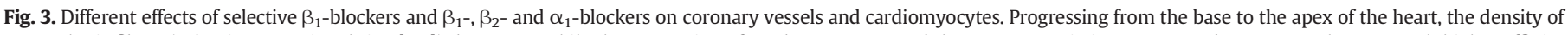

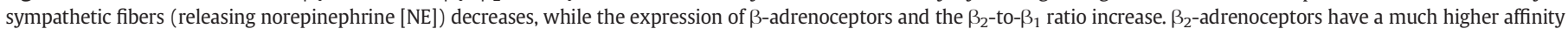

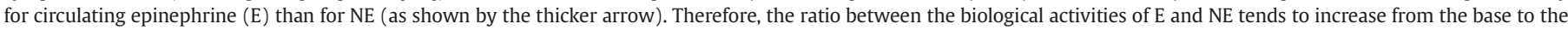

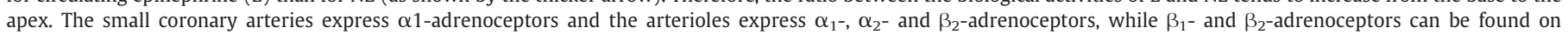
cardiomyocytes. The effects of selective $\beta_{1}$-blockers and non-selective, $\alpha_{1^{-}}, \beta_{1^{-}}$and $\beta_{2}$-adrenoceptor blockers are schematically reported. 


\section{Rationale for $\beta$-blocker therapy in TTS}

\subsection{Prevention of vasospasm}

As discussed above, a surge in sympathetic outflow might induce a spasm of small arteries and arterioles by activating $\alpha_{1-}$ and $\alpha_{2}$-adrenoceptors in the context of endothelial dysfunction and atherosclerosis $[20,37,38]$. Therefore, the possibility exists that selective $\beta_{1}$ blockers might elicit vasoconstriction by shifting catecholamines toward binding to $\alpha_{1}$ and $\alpha_{2}$-adrenoceptos [39]. Although the use of $\beta_{1}$ selective agents metoprolol [6] or esmolol [9] has not been associated with severe adverse effects in TTS, $\beta$-blockers with concomitant $\alpha$ blockade action such as carvedilol, labetalol or bucindolol might be preferred, as they can prevent the spasm of small arteries and arterioles $[40,41]$.

\subsection{Prevention of catecholamine toxicity}

It is generally accepted that chronically elevated stimulation of the cardiac $\beta$-adrenergic system is toxic to the heart, and that cardiotoxicity is mediated by $\beta_{1}$-adrenoceptor activation [42]. Among the supporting evidence, there are studies on transgenic mice showing that low-level (around 5-fold) overexpression of $\beta_{1}$-adrenoceptor leads to early and marked cardiomyopathy, while up to 100 -fold overexpression of $\beta_{2^{-}}$ adrenoceptors causes a significant increase in cardiac contractile force without the development of cardiac disease over 1 year [43]. In patients with $\mathrm{HF}$, downregulation of $\beta_{1}$-adrenoceptors acts as a protective mechanism against cardiotoxicity [42]. In the acute phase of TTS, pharmacological blockade of $\beta_{1}$-adrenoceptors might exert a similar protective function. Drugs with combined $\beta_{1^{-}}, \beta_{2^{-}}$and $\alpha_{1}$-blockade might prove more beneficial than selective $\beta_{1}$-blockers by not reversing the downregulation of $\beta_{1}$-adrenoceptors [44] and causing a prominent reduction of cardiac and systemic adrenergic drive [44-47], as previously demonstrated in the setting of HF.

\subsection{Attenuation of the depressed myocardial contractility}

As discussed above, $\beta_{2}$-adrenoceptor activation during the acute phase of TTS is a double-edged sword, because it induces protective depression of myocardial contractility that, however, contributes to the deterioration of ventricular function $[35,36]$. A selective $\beta_{1}$-blocker would leave $\beta_{2}$-adrenoceptors unblocked, and then able to mediate this cardiac protective response. $\beta$-blockers blocking both $\beta_{1}$ - and $\beta_{2}$ adrenoceptors might then promote the recovery from LV dysfunction while inhibiting the detrimental $\beta_{1}$ activation.

\section{Conclusions}

Although $\beta$-blockers are often used in patients with TTS, there are no specific recommendations regarding which $\beta$-blocker agents should be preferred in individual patients $[2,48]$. As a consequence, it remains unclear if the best option is a selective $\beta_{1}$-blocker (e.g., atenolol), a $\beta_{1}$ - and $\beta_{2}$-blocker (e.g., propranolol), or a $\beta$ - and $\alpha_{1}$-blocker drug (e.g., carvedilol, labetalol or bucindolol), which act as vasodilators because of their effects on $\alpha_{1}$ adrenoceptors. Based on our current understanding of TTS pathophsioogy $[24,25,49]$, there is a rationale to prefer non-selective $\beta$-blockers with vasodilating activity over $\beta 1$-selective drugs in the acute phase of TTS [50]. Although a clear-cut demonstration is lacking, we hypothesize that the reason why a $\beta$-blocker with vasodilating activity could be more effective than a selective $\beta_{1}$ blocker is threefold: 1 ) it might prevent coronary spasm even in the presence of endothelial dysfunction, 2) it might protect cardiomyocytes from catecholamine toxicity, and 3 ) it could relieve $\beta_{2}$-adrenoceptors mediated contractile dysfunction due to the G-protein switch. These mechanisms are recapitulated in Fig. 3. Nonetheless, we acknowledge that this proposal relies simply on pathophysiological considerations, and further evidence from preclinical and human studies is needed [8].

\section{Declaration of Competing Interest}

None.

\section{References}

[1] A. Prasad, G. Dangas, M. Srinivasan, J. Yu, B.J. Gersh, R. Mehran, G.W. Stone, Incidence and angiographic characteristics of patients with apical ballooning syndrome (takotsubo/stress cardiomyopathy) in the HORIZONS-AMI trial: an analysis from a multicenter, international study of ST-elevation myocardial infarction, Catheteriz. Cardiovasc. Intervent. Official J. Soc. Cardiac Angiogr. Intervent. 83 (2014) 343-348.

[2] J.R. Ghadri, I.S. Wittstein, A. Prasad, S. Sharkey, K. Dote, Y.J. Akashi, V.L. Cammann, F. Crea, L. Galiuto, W. Desmet, T. Yoshida, R. Manfredini, I. Eitel, M. Kosuge, H.M. Nef, A. Deshmukh, A. Lerman, E. Bossone, R. Citro, T. Ueyama, D. Corrado, S. Kurisu, F. Ruschitzka, D. Winchester, A.R. Lyon, E. Omerovic, J.J. Bax, P. Meimoun, G. Tarantini, C. Rihal, S. YH, F. Migliore, J.D. Horowitz, H. Shimokawa, T.F. Lüscher, C. Templin, International Expert Consensus Document on Takotsubo Syndrome (Part I): Clinical Characteristics, Diagnostic Criteria, and Pathophysiology, Eur. Heart J. 39 (2018) 2032-2046.

[3] C. Templin, J.R. Ghadri, J. Diekmann, L.C. Napp, D.R. Bataiosu, M. Jaguszewski, V.L. Cammann, A. Sarcon, V. Geyer, C.A. Neumann, B. Seifert, J. Hellermann, M. Schwyzer, K. Eisenhardt, J. Jenewein, J. Franke, H.A. Katus, C. Burgdorf, H. Schunkert, C. Moeller, H. Thiele, J. Bauersachs, C. Tschöpe, H.P. Schultheiss, C.A. Laney, L. Rajan, G. Michels, R. Pfister, C. Ukena, M. Böhm, R. Erbel, A. Cuneo, K.H. Kuck, C. Jacobshagen, G. Hasenfuss, M. Karakas, W. Koenig, W. Rottbauer, S.M. Said, R.C. Braun-Dullaeus, F. Cuculi, A. Banning, T.A. Fischer, T. Vasankari, K.E. Airaksinen, M. Fijalkowski, A. Rynkiewicz, M. Pawlak, G. Opolski, R. Dworakowski, P. MacCarthy, C. Kaiser, S. Osswald, L. Galiuto, F. Crea, W. Dichtl, W.M. Franz, K. Empen, S.B. Felix, C. Delmas, O. Lairez, P. Erne, J.J. Bax, I. Ford, F. Ruschitzka, A. Prasad, T.F. Lüscher, Clinical features and outcomes of Takotsubo (Stress) cardiomyopathy, New Engl. J. Med 373 (2015) 929-938.

[4] O. De Backer, P. Debonnaire, S. Gevaert, L. Missault, P. Gheeraert, L. Muyldermans, Prevalence, associated factors and management implications of left ventricular outflow tract obstruction in takotsubo cardiomyopathy: a two-year, two-center experience, BMC Cardiovasc. Disord. 14 (2014) 147.

[5] J.R. Ghadri, I.S. Wittstein, A. Prasad, S. Sharkey, K. Dote, Y.J. Akashi, V.L. Cammann, F. Crea, L. Galiuto, W. Desmet, T. Yoshida, R. Manfredini, I. Eitel, M. Kosuge, H.M. Nef, A. Deshmukh, A. Lerman, E. Bossone, R. Citro, T. Ueyama, D. Corrado, S. Kurisu, F. Ruschitzka, D. Winchester, A.R. Lyon, E. Omerovic, J.J. Bax, P. Meimoun, G. Tarantini, C. Rihal, S. YH, F. Migliore, J.D. Horowitz, H. Shimokawa, T.F. Lüscher, C. Templin, International expert consensus document on Takotsubo syndrome (Part II): diagnostic workup, outcome, and management, Eur. Heart J. 39 (2018) 2047-2062.

[6] Y. Izumi, H. Okatani, M. Shiota, T. Nakao, R. Ise, G. Kito, K. Miura, H. Iwao, Effects of metoprolol on epinephrine-induced takotsubo-like left ventricular dysfunction in non-human primates, Hypertension Res. Off. J. Jpn. Soc. Hypertension. 32 (2009) 339-346.

[7] T. Ueyama, K. Kasamatsu, T. Hano, K. Yamamoto, Y. Tsuruo, I. Nishio, Emotional stress induces transient left ventricular hypocontraction in the rat via activation of cardiac adrenoceptors: a possible animal model of 'tako-tsubo' cardiomyopathy, Circul. J. Off. J. Jpn. Circul. Soc. 66 (2002) 712-713.

[8] S. YH, P. Tornvall, Reply to: metoprolol, or propranolol, or carvedilol, or labetalol, for patients with takotsubo syndrome? Clin. Autonom. Res. Off. J. Clin. Autonom. Res. Soc 28 (2018) 133-134.

[9] F. Santoro, R. Ieva, A. Ferraretti, M. Fanelli, F. Musaico, N. Tarantino, L.D. Martino, L.D. Gennaro, P. Caldarola, M.D. Biase, N.D. Brunetti, Hemodynamic effects, safety, and feasibility of intravenous esmolol infusion during Takotsubo cardiomyopathy with left ventricular outflow tract obstruction: results from a multicenter registry, Cardiovasc. Ther. 34 (2016) 161-166.

[10] T. Isogai, H. Matsui, H. Tanaka, K. Fushimi, H. Yasunaga, Early $\beta$-blocker use and inhospital mortality in patients with Takotsubo cardiomyopathy, Heart 102 (2016) 1029-1035.

[11] S. Kumar, S. Kaushik, A. Nautiyal, S.K. Choudhary, B.L. Kayastha, N. Mostow, J.M. Lazar, Cardiac rupture in Takotsubo cardiomyopathy: a systematic review, Clin. Cardiol. 34 (2011) 672-676.

[12] K. Singh, K. Carson, Z. Usmani, G. Sawhney, R. Shah, J. Horowitz, Systematic review and meta-analysis of incidence and correlates of recurrence of Takotsubo cardiomyopathy, Int. J. Cardiol. 174 (2014) 696-701.

[13] M. Bonacchi, A. Vannini, G. Harmelin, S. Batacchi, M. Bugetti, G. Sani, A. Peris, Inverted-Takotsubo cardiomyopathy: severe refractory heart failure in polytrauma patients saved by emergency extracorporeal life support, Interact. Cardiovasc. Thorac. Surg. 20 (2015) 365-371.

[14] F. Santoro, R. Ieva, F. Musaico, A. Ferraretti, G. Triggiani, N. Tarantino, M. Di Biase, N.D. Brunetti, Lack of efficacy of drug therapy in preventing takotsubo cardiomyopathy recurrence: a meta-analysis, Clin. Cardiol. 37 (2014) 434-439.

[15] J.H. Coote, R.A. Chauhan, The sympathetic innervation of the heart: important new insights, Autonom. Neurosci. Basic Clin. 199 (2016) 17-23.

[16] G.L. Todd, G. Baroldi, G.M. Pieper, F.C. Clayton, R.S. Eliot, Experimental catecholamine-induced myocardial necrosis. I. Morphology, quantification and 
regional distribution of acute contraction band lesions, J. Mol. Cell. Cardiol. 17 (1985) 317-338.

[17] P.G. Camici, O.E. Rimoldi, F. Crea, Coronary microvascular dysfunction, Braunwald's Heart Disease: A Textbook of Cardiovascular Medicine, 11th editionElsevier, 2018.

[18] R.A. Cohen, J.T. Shepherd, P.M. Vanhoutte, Prejunctional and postjunctional actions of endogenous norepinephrine at the sympathetic neuroeffector junction in canine coronary arteries, Circ. Res. 52 (1983) 16-25.

[19] W.M. Chilian, Functional distribution of alpha 1- and alpha 2-adrenergic receptors in the coronary microcirculation, Circulation. 84 (1991) 2108-2122.

[20] G. Heusch, D. Baumgart, P. Camici, W. Chilian, L. Gregorini, O. Hess, C. Indolfi, O. Rimoldi, Alpha-adrenergic coronary vasoconstriction and myocardial ischemia in humans, Circulation. 101 (2000) 689-694.

[21] M. Naegele, A.J. Flammer, F. Enseleit, S. Roas, M. Frank, A. Hirt, P. Kaiser, S. Cantatore, C. Templin, G. Fröhlich, M. Romanens, T.F. Lüscher, F. Ruschitzka, G. Noll, I. Sudano, Endothelial function and sympathetic nervous system activity in patients with Takotsubo syndrome, Int. J. Cardiol. 224 (2016) 226-230.

[22] L. Galiuto, A.R. De Caterina, A. Porfidia, L. Paraggio, S. Barchetta, G. Locorotondo, A.G. Rebuzzi, F. Crea, Reversible coronary microvascular dysfunction: a common pathogenetic mechanism in apical ballooning or Tako-Tsubo syndrome, Eur. Heart J. 31 (2010) 1319-1327.

[23] M. Feola, S. Chauvie, G.L. Rosso, A. Biggi, F. Ribichini, M. Bobbio, Reversible impairment of coronary flow reserve in takotsubo cardiomyopathy: a myocardial PET study, J. Nucl. Cardiol. Off. Publ. Am. Soc. Nucl. Cardiol. 15 (2008) 811-817.

[24] F. Pelliccia, J.C. Kaski, F. Crea, P.G. Camici, Pathophysiology of Takotsubo syndrome, Circulation. 135 (2017) 2426-2441.

[25] A.R. Lyon, R. Citro, B. Schneider, O. Morel, J.R. Ghadri, C. Templin, E. Omerovic, Pathophysiology of Takotsubo syndrome: JACC state-of-the-art review, J. Am. Coll. Cardiol. 77 (2021) 902-921.

[26] C. Basso, G. Thiene, The pathophysiology of myocardial reperfusion: a pathologist's perspective, Heart 92 (2006) 1559-1562.

[27] H.M. Nef, H. Möllmann, C. Troidl, S. Kostin, S. Voss, P. Hilpert, C.B. Behrens, A. Rolf, J. Rixe, M. Weber, C.W. Hamm, A. Elsässer, Abnormalities in intracellular Ca2+ regulation contribute to the pathomechanism of Tako-Tsubo cardiomyopathy, Eur. Heart J. 30 (2009) 2155-2164.

[28] Y. Shao, B. Redfors, M. Ståhlman, M.S. Täng, A. Miljanovic, H. Möllmann, C. Troidl, S. Szardien, C. Hamm, H. Nef, J. Borén, E. Omerovic, A mouse model reveals an important role for catecholamine-induced lipotoxicity in the pathogenesis of stressinduced cardiomyopathy, Eur. J. Heart Fail. 15 (2013) 9-22.

[29] M. Wallner, J.M. Duran, S. Mohsin, C.D. Troupes, D. Vanhoutte, G. Borghetti, R.J. Vagnozzi, P. Gross, D. Yu, D.M. Trappanese, H. Kubo, A. Toib, T.E. Sharp 3rd, S.C. Harper, M.A. Volkert, T. Starosta, E.A. Feldsott, R.M. Berretta, T. Wang, M.F. Barbe, J.D. Molkentin, S.R. Houser, Acute catecholamine exposure causes reversible myocyte injury without cardiac regeneration, Circ. Res. 119 (2016) 865-879.

[30] W. Raab, E. Stark, W.H. Macmillan, W.R. Gigee, Sympathogenic origin and antiadrenergic prevention of stress-induced myocardial lesions, Am. J. Cardiol. 8 (1961) 203-211.

[31] J.F. Heubach, U. Ravens, A.J. Kaumann, Epinephrine activates both Gs and Gi pathways, but norepinephrine activates only the Gs pathway through human beta2-adrenoceptors overexpressed in mouse heart, Mol. Pharmacol. 65 (2004) 1313-1322.

[32] T. Nakano, K. Onoue, Y. Nakada, H. Nakagawa, T. Kumazawa, T. Ueda, T. Nishida, T. Soeda, S. Okayama, M. Watanabe, H. Kawata, R. Kawakami, M. Horii, H. Okura, S. Uemura, K. Hatakeyama, Y. Sakaguchi, Y. Saito, Alteration of $\beta$-adrenoceptor signaling in left ventricle of acute phase Takotsubo syndrome: a human study, Sci. Rep. 8 (2018) 12731.

[33] C. Hoffmann, M.R. Leitz, S. Oberdorf-Maass, M.J. Lohse, K.N. Klotz, Comparative pharmacology of human beta-adrenergic receptor subtypes-characterization of stably transfected receptors in CHO cells, Naunyn Schmiedeberg's Arch. Pharmacol. 369 (2004) 151-159.
[34] H. Mori, S. Ishikawa, S. Kojima, J. Hayashi, Y. Watanabe, J.I. Hoffman, H. Okino, Increased responsiveness of left ventricular apical myocardium to adrenergic stimuli, Cardiovasc. Res. 27 (1993) 192-198.

[35] H. Paur, P.T. Wright, M.B. Sikkel, M.H. Tranter, C. Mansfield, P. O’Gara, D.J. Stuckey, V.O. Nikolaev, I. Diakonov, L. Pannell, H. Gong, H. Sun, N.S. Peters, M. Petrou, Z. Zheng, J. Gorelik, A.R. Lyon, S.E. Harding, High levels of circulating epinephrine trigger apical cardiodepression in a $\beta 2$-adrenergic receptor/Gi-dependent manner: a new model of Takotsubo cardiomyopathy, Circulation. 126 (2012) 697-706.

[36] A.R. Lyon, P.S. Rees, S. Prasad, P.A. Poole-Wilson, S.E. Harding, Stress (Takotsubo) cardiomyopathy-a novel pathophysiological hypothesis to explain catecholamineinduced acute myocardial stunning, Nat. Clin. Pract. Cardiovasc. Med. 5 (2008) 22-29.

[37] G. Heusch, A. Deussen, J. Schipke, V. Thämer, Alpha 1- and alpha 2-adrenoceptormediated vasoconstriction of large and small canine coronary arteries in vivo, J. Cardiovasc. Pharmacol. 6 (1984) 961-968.

[38] J.A. Vita, C.B. Treasure, A.C. Yeung, V.I. Vekshtein, G.M. Fantasia, R.D. Fish, P. Ganz, A.P. Selwyn, Patients with evidence of coronary endothelial dysfunction as assessed by acetylcholine infusion demonstrate marked increase in sensitivity to constrictor effects of catecholamines, Circulation. 85 (1992) 1390-1397.

[39] Y. Tamura, K. Sakata, M.A. Kawashiri, M. Yamagishi, Multi-vessel coronary vasospasm after beta-blocker administration, Intern. Med. (Tokyo, Japan) 57 (2018) 3219-3220.

[40] D. Tzivoni, A. Keren, J. Benhorin, S. Gottlieb, D. Atlas, S. Stern, Prazosin therapy for refractory variant angina, Am. Heart J. 105 (1983) 262-266.

[41] M.D. Winniford, N. Filipchuk, L.D. Hillis, Alpha-adrenergic blockade for variant angina: a long-term, double-blind, randomized trial, Circulation. 67 (1983) 1185-1188.

[42] R.J. Lefkowitz, H.A. Rockman, W.J. Koch, Catecholamines, cardiac beta-adrenergic receptors, and heart failure, Circulation. 101 (2000) 1634-1637.

[43] S.B. Liggett, N.M. Tepe, J.N. Lorenz, A.M. Canning, T.D. Jantz, S. Mitarai, A. Yatani, G.W. Dorn 2nd., Early and delayed consequences of beta(2)-adrenergic receptor overexpression in mouse hearts: critical role for expression level, Circulation. 101 (2000) 1707-1714.

[44] E.M. Gilbert, W.T. Abraham, S. Olsen, B. Hattler, M. White, P. Mealy, P. Larrabee, M.R. Bristow, Comparative hemodynamic, left ventricular functional, and antiadrenergic effects of chronic treatment with metoprolol versus carvedilol in the failing heart, Circulation. 94 (1996) 2817-2825.

[45] E.M. Gilbert, J.L. Anderson, D. Deitchman, F.G. Yanowitz, J.B. O'Connell, D.G. Renlund, M. Bartholomew, P.C. Mealey, P. Larrabee, M.R. Bristow, Long-term beta-blocker vasodilator therapy improves cardiac function in idiopathic dilated cardiomyopathy: a double-blind, randomized study of bucindolol versus placebo, Am. J. Med. 88 (1990) 223-229.

[46] M.R. Bristow, P. Larrabee, W. Minobe, R. Roden, L. Skerl, J. Klein, D. Handwerger, J.D. Port, B. Müller-Beckmann, Receptor pharmacology of carvedilol in the human heart, J. Cardiovasc. Pharmacol. 19 (Suppl. 1) (1992) S68-S80.

[47] M.R. Bristow, R.L. Roden, B.D. Lowes, E.M. Gilbert, E.J. Eichhorn, The role of thirdgeneration beta-blocking agents in chronic heart failure, Clin. Cardiol. 21 (1998) I3-13.

[48] A.R. Lyon, E. Bossone, B. Schneider, U. Sechtem, R. Citro, S.R. Underwood, M.N. Sheppard, G.A. Figtree, G. Parodi, Y.J. Akashi, F. Ruschitzka, G. Filippatos, A Mebazaa, E. Omerovic, Current state of knowledge on Takotsubo syndrome: a position statement from the taskforce on Takotsubo syndrome of the Heart Failure Association of the European Society of Cardiology, Eur. J. Heart Fail. 18 (2016) 8-27.

[49] L. Boussel, G. Herigault, A. de la Vega, M. Nonent, P.C. Douek, J.M. Serfaty, Swallowing, arterial pulsation, and breathing induce motion artifacts in carotid artery MRI, J. Magnetic Reson. Imaging JMRI. 23 (2006) 413-415.

[50] J.E. Madias, Metoprolol, propranolol, carvedilol, or labetalol for patients with Takotsubo syndrome? Clin. Autonom. Res. Off. J. Clin. Autonom. Res. Soc. 28 (2018) 131-132. 